\title{
Nucleation delay and the textural development during crystalization of a hydrous felsic melt
}

\author{
MONIKA K. RUSIECKA ${ }^{1 *}$, DON R. BAKER ${ }^{1}$ \\ ${ }^{1}$ Department of Earth and Planetary Sciences, \\ McGill University, 3450 rue University, Montreal H3A 0E8 \\ Canada*monika.rusiecka@mail.mcgill.ca
}

We conducted experiments on hydrous, boron-bearing rhyolitic composition prepared from Lake County Obsidian (LCO). The experiments were conducted at $600 \mathrm{MPa}$ and temperatures of $500-800{ }^{\circ} \mathrm{C}$. The durations were $9 \mathrm{~h}$ to 2 months. The experiments were compared to recently developed nucleation delay study [1]. The delay time varied between $\sim 1$ month at undercooling of $340{ }^{\circ} \mathrm{C}\left(500{ }^{\circ} \mathrm{C}\right)$ and $\sim 12 \mathrm{~h}$ at undercooling of $40{ }^{\circ} \mathrm{C}\left(800{ }^{\circ} \mathrm{C}\right)$. The textures produced in the experiments were quantified using fractal analysis.

In all the experiments, nucleation occurred heterogeneously on the capsule walls. The experimental results at different degrees of undercooling and with different nucleation delays produced different textures. In all experiments, except for the lowest undercooling $\left(\Delta \mathrm{T}=40^{\circ} \mathrm{C}\right)$, quartz and alkali feldspar produced different types of intergrowths. In experiments at the highest experimental undercooling $\left(\Delta \mathrm{T}=340{ }^{\circ} \mathrm{C}\right)$ quartz and feldspar form vermicular intergrowths where the width of the crystals is $1 \mu \mathrm{m}$ and less. At moderate undercooling the quartz and felspar intergrowths resemble graphic granite seen in granitic pegmatites. At the lowest undercoolings in an experiment conducted for $24 \mathrm{~h}$, only quartz nucleated and formed euhedral crystals.

To quantify the textural observations, we conducted the fractal analysis of the backscattered electron images of the experimental run products following the techniques of Baker et al. (2018, [2]). The measurements of the textures produced at $500{ }^{\circ} \mathrm{C}$ plot close together at relatively high fractal dimensions, and low lacunarity (0.2-0.35), when compared to the results of Baker et al. (2018, [2]). The measurements of the textures formed at $700{ }^{\circ} \mathrm{C}$ plot at similar fractal dimensions but show much more variation in lacunarity (0.25-0.6).

[1] Rusiecka, M. K., Bilodeau, M., Baker, D. R. (under review). Contributions to Mineralogy and Petrology. [2] Baker, D. R., Sirbescu, M-L. C., Maneta, V., Webber, K. L., Simmons, W. B. (2018). Canadian Mineralogist, 56, 625643. 